\title{
The possible regulatory effect of the PD-1/PD-L1 signaling pathway on Tregs in ovarian cancer
}

\author{
Jian-Xia Chen, Xi-Juan Yi, Shan-Xia Gao and Jin-Xia Sun \\ Department of Reproductive Medicine, Linyi Central Hospital, Linyi City, Shandong, China
}

\begin{abstract}
Aim of this study was to investigate the possible regulatory effect of the programmed death-1 (PD-1)/programmed death ligand-1 (PD-L1) signaling pathway on Tregs in ovarian cancer. Immunohistochemistry was used to detect the expression of PD-L1 and PD-1 and the presence of $\mathrm{FOXP}^{+}$Tregs in ovarian cancer. Then, ovarian cancer HO8910 cells were subjected to transfection with PD-L1 siRNA in vitro. CCK-8, Transwell and wound healing assays were performed to detect the biological behaviors of ovarian cancer cells. Human T-cells isolated from human peripheral blood were cocultured with HO8910 cells, which were divided into the Control, TGF- $\beta$, and TGF- $\beta^{+}$antiPD-L1 groups. The proportion of differentiated Tregs was detected by flow cytometry. Mouse models of ovarian cancer were established, and PD-L1 antibody therapy was administered. Tumor growth and Treg recruitment were observed. PD-L1, PD- 1 and FOXP $3^{+}$Tregs were found in ovarian cancer tissue. Patients with tumors with an advanced stage and low differentiation and lymph node metastasis had significantly higher levels of PD-1, PD-L1 and FOXP3 $3^{+}$Tregs. After transfection with PD-L1 siRNA, HO8910 cells showed a significant reduction in PD-L1 expression, proliferation, migration and invasion. After T-cells were cocultured with ovarian cancer cells, the TGF- $\beta^{+}$anti-PD-L1 group showed a substantial decline in the differentiation of T-cells into Tregs compared with the TGF- $\beta$ group. Moreover, mice in the anti-PD-L1 group had significantly reduced tumor growth rates, Treg proportions in the tumor microenvironment, and FOXP3 expression.
\end{abstract}

Key words: Ovarian cancer - PD-1 - PD-L1 - Tregs - Tumor immune escape

\section{Introduction}

Ovarian cancer (OC) is one of the most common malignancies occurring in the female reproductive system and has an incidence that is ranked only behind cervical cancer and endometrial cancer (Fekonja et al. 2015). The incidence rates of $\mathrm{OC}$ have been rising gradually during the last two decades, posing a great threat to the life and health of women (Tang et al. 2010; Hou et al. 2017). Due to the nonspecificity of early OC symptoms, approximately $60-70 \%$ of OC patients have usually reached the late/advanced stage at the time of diagnosis (Cho and Shih 2009). Although the major therapy for OC is surgery combined with chemotherapy, unfortunately, over $70 \%$ of patients eventually show resist-

Correspondence to: Jin-Xia Sun, Department of Reproductive Medicine, Linyi Central Hospital, No. 17, Jiankang Road, Linyi City, Shandong 276400, China

E-mail: cjx_cjx2019@outlook.com ance to chemotherapeutic drugs, which leads to treatment failure and a less than 30\% 5-year survival rate for patients with advanced OC (Yoshida et al. 2011; Siegel et al. 2018). Recently, immunotherapy has attracted much attention in oncology therapy research as a potential radical cure for cancers (Wefers et al. 2015). Therefore, an understanding of tumor immune escape is of great clinical significance for finding new therapeutic targets for cancers.

Programmed death-1 (PD-1) belongs to the CD28 family and tends to be highly expressed on the surfaces of activated T/B lymphocytes and monocytes (Okazaki and Honjo 2007; Keir et al. 2008), while programmed death ligand-1 (PD-L1), which is one of the PD-1 ligands, is a member of the B7 family and can be expressed on the surfaces of various cells, including activated T/B lymphocytes, monocytes, mesenchymal cells, and even some epithelial cells (Blank and Mackensen 2007; Topalian et al. 2012). Under physiological conditions, PD-L1 interacts with its receptor $\mathrm{PD}-1$ to participate in negative immune regula- 
tion, thereby maintaining the immune homeostasis of the body (Hafalla et al. 2012; Nowicki et al. 2017). Some recent studies found that the PD-1/PD-L1 pathway can inhibit the antitumor immune response of the body and play a large role in tumor immune escape (Pai et al. 2016; Kumar et al. 2017). Studies that have used anti-PD-L1 antibodies have subsequently identified significant antitumor effects against several human cancers (Hamid et al. 2013; Mehnert et al. 2019). In addition, previous studies have also proved that anti-PD-L1 and anti-PD-1 antibodies can play a critical role in the adjuvant therapy of OC (Jacobs et al. 2009; Hsu et al. 2017). Hamanishi et al. (2015) indicated that anti-PD-L1 antibody was also expected to have therapeutic effects in OC. Most PD-L1 antibodies are of the IgG4 isotype or the Fc-modified IgG1 isotype, both of which inhibit the interaction of PD-1 on immune cells with PD-L1 on tumor cells (Fujii et al. 2016). Avelumab, a fully humanized IgG1 antiPD-L1 monoclonal antibody $(\mathrm{mAb})$, is the only anti-PD-L1 $\mathrm{mAb}$ that both induces antibody-dependent cell-mediated cytotoxicity (ADCC) and blocks the PD-1/PD-L1 pathway (Boyerinas et al. 2015). A previous study reported that avelumab enhanced ADCC in several cancer cell lines expressing PD-L1 (Boyerinas et al. 2015). Avelumab has been approved for the treatment of therapy-refractory multiple solid tumors (Gatalica et al. 2014) and early clinical trials in OC are currently being evaluated (Pujade-Lauraine et al. 2018). Although the clinical effects of avelumab therapies have received attention, the precise mechanism underlying the effects of these treatments remains elusive.

Regulatory $\mathrm{T}$ cells (Tregs) are a unique subset of $\mathrm{CD} 4^{+}$ helper T-lymphocytes (T-cells) that are characterized by a CD $4^{+} \mathrm{CD} 25^{+}$phenotype (Hafeez et al. 2014; Webb et al. 2016) and play key roles in the immune response by suppressing the differentiation and proliferation of various immune cells (Han et al. 2012, 2015). When there is a tumor in the body, Tregs, which serve as a class of important negative immune regulatory cells, can reduce the functioning of antitumorspecific T-cells in various ways, thereby inducing the occurrence of tumor immune escape (Sakaguchi 2008; Wolf et al. 2015). PD-1 molecules are highly expressed on the surfaces of Tregs and greatly affect the growth and development of Tregs (Polanczyk et al. 2007; Ding et al. 2011). Jacobs et al. (2009) found a correlation between the infiltration of a large number of $\mathrm{CD} 4^{+} \mathrm{FOXP} 3^{+} \mathrm{CD} 25^{\text {high }} \mathrm{CD} 127^{\text {low }}$ Tregs and the expression of PD-1/PD-L1 molecules. Nevertheless, the relationship of PD-1/PD-L1 and Tregs with the occurrence, progression and immune responses of OC has not been clarified.

Therefore, we demonstrate the potential of anti-PD-L1 $\mathrm{mAb}$ avelumab therapy by using in vitro assays to investigate the regulatory mechanism underlying the effects of the PD-1/PD-L1 pathway and Tregs on the tumor immune response to provide a new theoretical basis for the immunotherapy of tumors.

\section{Materials and Methods}

\section{Study subjects}

From January 2017 to December 2018, 95 OC patients who received surgery in Linyi Central Hospital were recruited as study subjects. The ages of these patients ranged from $28-$ 71 years with a mean age of $49.43 \pm 11.88$ years. All patients did not receive any chemotherapy or radiotherapy before the surgery. OC patients were staged using the International Federation of Gynecology and Obstetrics (FIGO) staging system (Keyver-Paik et al. 2013). Among all cases, 59 cases were stage I-II, and 36 cases were stage III-IV. According to the World Health Organization (WHO) classification system (Kaku et al. 2003), there were 65 cases of G1 + G2 (high differentiation and medium differentiation) and 30 cases of G3 (low differentiation). In addition, 33 patients showed lymph node metastasis, and 62 showed no lymph node metastasis. Meanwhile, normal ovarian tissues (56 cases in total) used as the control group were obtained from randomly selected perimenopausal women who underwent surgery for doubleappendage resection due to myopia of the uterus in Linyi Central Hospital during the same time period. The ages of the control subjects were 30-65 years, with a mean age of $50.12 \pm 10.79$ years. Tissues were cryopreserved in liquid nitrogen at $-80^{\circ} \mathrm{C}$ within $5 \mathrm{~min}$ of isolation from the body. All tissues were fixed in 10\% formaldehyde and embedded in conventional paraffin.

\section{Immunohistochemical staining}

The tissue sections were deparaffinized in xylene and dehydrated with gradient alcohol. The sections were then treated with 3\% hydrogen peroxide to block endogenous peroxidase activity for $10 \mathrm{~min}$ and washed with phosphate buffered saline (PBS) buffer 3 times (e.g., 2 min each time). Then, the sections were incubated with primary antibodies against mouse anti-human PD-L1 mAb (Novus Biologicals LLC), mouse anti-human PD-1 mAb (Beijing ZSGB BIO LLC) and mouse anti-human FOXP3 mAb (Bio Legend, USA) overnight at $4^{\circ} \mathrm{C}$. This was followed by incubation with the Envision secondary antibody (Beijing ZSGB BIO LLC) for $30 \mathrm{~min}$ at room temperature. Next, the tissue sections were removed and washed with PBS 3 times for 2 min each time. Finally, 3,3'-diaminobenzidine (DAB) reagent (Beijing ZSGB BIO LLC) was used as a chromogen for visualization. Next, the sections were counterstained with hematoxylin and mounted with neutral resin.

\section{Flow cytometry}

OC cell lines (HO8910, OVCAR5, SKOV3, and A2780C70) were purchased from ATCC in the USA. OC cells 
$\left(1 \times 10^{6} / \mathrm{ml}\right)$ were collected and centrifuged twice in sterile PBS before being resuspended in $100 \mu$ of sterile PBS. Next, the cells were immediately labeled with $5 \mu \mathrm{l}$ PE-PD-L1 Ab (Biolengend, USA) at $4^{\circ} \mathrm{C}$ for $30 \mathrm{~min}$ in the dark, followed by the addition of $5 \mathrm{ml}$ sterile PBS and 2 centrifugations. The labeled cells were resuspended in $500 \mu \mathrm{l}$ sterile PBS and then analyzed using a flow cytometer (CytomicsTM FC500, Beckman Coulter, USA). Cells not labeled with antibodies were used as the negative controls.

\section{Cell grouping and transfection}

Human OC HO8910 cells were divided into three groups: Control group (cells without transfection), siRNA NC group (cells transfected with negative control siRNA) and siRNA PD-L1 group (cells transfected with PD-L1 siRNA). Transfection was performed by using the Lipofectamine ${ }^{\text {TM }}$ 2000 reagent (Invitrogen, USA) in accordance with the manufacturer's instructions. Approximately $48 \mathrm{~h}$ after transfection, the cells were collected for subsequent experiments.

\section{Cell counting kit-8 (CCK-8) assay}

In brief, the cells were seeded into 96 -well plates at $5 \times 10^{3} / 100 \mu \mathrm{l} /$ well, and three replicates were used along with one blank control group (only culture medium was added). After culturing at $37^{\circ} \mathrm{C}$ in $5 \% \mathrm{CO}_{2}$, each well in the plates was incubated with $10 \mu \mathrm{l}$ cholecystokinin-8 (CCK-8) reagent (Dojindo Molecular Technologies, Inc., Japan) for $4 \mathrm{~h}$. Then, the optical density (OD) value of each well was measured in a microplate reader.

\section{Transwell assay}

Matrigel and serum-free cell culture fluid were mixed together at a ratio of $1: 3$, and $30 \mu \mathrm{l}$ of the mixture was applied to the inner surface of the polycarbonate membrane of the Transwell chamber (Corning, USA) for $2 \mathrm{~h}$ at $37^{\circ} \mathrm{C}$. Then, the OC cells were starved for $6 \mathrm{~h}$ and were then inoculated into the upper chamber of each Transwell plate, and the lower chamber was covered by $500 \mu \mathrm{l}$ cell culture medium that contained $10 \%$ fetal bovine serum. The Transwell plates were incubated at $37^{\circ} \mathrm{C}$ in $5 \% \mathrm{CO}_{2}$ for $12 \mathrm{~h}$. Finally, the Transwell chamber was removed, and the membrane was stained with $1 \%$ crystal violet. The invading cells penetrating the membrane were counted in six randomly selected high-power fields and quantified using ImageJ software.

\section{Wound healing assay}

The cells of each group were collected at the logarithmic growth phase and digested with $0.25 \%$ trypsin to generate a single-cell suspension. The cells were inoculated into 6 -well plates at a density of $2.0 \times 10^{5} / \mathrm{ml}$ by adding $2 \mathrm{ml}$ to each well. When the cells grew to approximately $80 \%$ confluency, the pipette tip was used to draw a straight line across the surface of the culture plate. Then, the cells were cultured for $48 \mathrm{~h}$ before observing the wound healing in each group.

\section{Preparation of human peripheral T-cells}

Fresh heparin obtained from healthy people $(30 \mathrm{ml})$ was used for anti-coagulation, and the Ficoll-Hypaque gradient centrifugation technique was used for the isolation of human peripheral blood mononuclear cells (PBMCs). Sterile PBS was used to suspend the PBMCs, and the density was adjusted to $5 \times 10^{7} / \mathrm{ml}$ before transferring the cells into tubes. An EasySep ${ }^{\mathrm{Ts}}$ human T-cell enrichment kit $(50 \mu \mathrm{l} / \mathrm{ml})$ was used after $10 \mathrm{~min}$ of incubation to perform negative selection. The EasySep magnetic beads were aspirated at least 5 times to avoid an uneven distribution. Magnetic beads were added to $50 \mu \mathrm{l} / \mathrm{ml}$ cell suspension, which was aspirated 2-3 times in the tube to achieve the even distribution of cells and magnetic beads. Next, the cells were incubated for $5 \mathrm{~min}$ at room temperature and transferred into a new tube by inclining the tube and beads at the same time. The cells in the new tube were human peripheral T-cells.

\section{Coculture of human OC cells and T-cells}

Activated T-cells were added to 96 -well plates at $1 \times 10^{4}$ cells/ well. Cells were divided into three groups: Control group (OC HO8910 cells + T-cells $+10 \mu \mathrm{g} / \mathrm{ml}$ Phytohemagglutinin (PHA)), TGF- $\beta$ group (OC HO8910 cells + T-cells + $10 \mu \mathrm{g} / \mathrm{ml}$ PHA $+1 \mathrm{ng} / \mathrm{ml}$ TGF- $\beta)$, and TGF- $\beta+$ anti-PD-L1 group (OC HO8910 cells + T-cells $+10 \mu \mathrm{g} / \mathrm{ml} \mathrm{PHA}+1 \mathrm{ng} /$ $\mathrm{ml} \mathrm{TGF}-\beta+10 \mu \mathrm{g} / \mathrm{ml}$ anti-PD-L1 mAb (avelumab)). After $72 \mathrm{~h}$ of coculture, flow cytometry was used to detect the percentage of differentiated Tregs. The anti-PD-L1 mAb avelumab was obtained from EMD Serono, Inc., Billerica, MA, USA.

\section{Mouse model of OC and PD-L1 antibody therapy}

Female C57BL/ 6 mice aged 6-8 weeks (provided by Shanghai SLAC Laboratory Animal Co., Ltd) were transplanted with OC cells (HO8910, $2 \times 10^{4}$ cells per mouse) by subcutaneous injection into the right lower abdomen. Four days later, subcutaneous nodules could be palpated. Mice were randomly divided into anti-PD-L1 group and Control group (10 mice in each group) and injected subcutaneously with PD-L1 antibody (100 $\mu \mathrm{g}$ per mouse) and homotypic IgG (control), respectively. One week later, another round of inoculation 
was performed. The length and diameter of the nodules were measured once every three days, and the average diameter was calculated as (longest diameter + shortest diameter) $/ 2$. After 21 days, the mice were killed, and tumor tissues were removed to generate single-cell suspensions. For flow cytometry detection, anti-CD4-FITC and anti-CD25-PC5 were used, and cells were fixed and labeled with anti- FOXP3-PE to detect the amount of Tregs.

Quantitative real-time reverse transcription polymerase chain reaction ( $q R T-P C R$ )

TRIzol (Invitrogen, USA) was used to extract total RNA from cells, and the concentration and purity of the RNA were determined. Then, cDNA synthesis was performed using the PrimeScript RT reagent kit (Takara). The primers were designed and synthesized by Shanghai GenePharma Co., Ltd. The PD-L1 primers included upstream 5'-TGCAGGGCATTCCAGAAAGA-3' and downstream 5'-ATGCGTTCAGCAAATGCCAG-3'; the FOXP3 primers included upstream 5'-CGAAGCTTATGCCCAACCCCAGGCCTG-3' and downstream 5'-CGGGATCCTCAGGGGCCAGGTGTAGGGTTG-3'; and the $\beta$-actin primers included

Table 1. The correlation of PD-1 and PD-L1 expressions with $\mathrm{FOXP}^{+}$Tregs in patients with ovarian cancer

\begin{tabular}{lcccccc}
\hline \multirow{2}{*}{$\begin{array}{l}\text { Foxp3 } \\
\text { Tregs }\end{array}$} & \multicolumn{2}{c}{ PD-1 } & $p$ & \multicolumn{2}{c}{ PD-L1 } & $p$ \\
\cline { 2 - 7 } & + & - & & + & - & \\
\hline+ & 34 & 5 & $<0.001$ & 36 & 3 & $<0.001$ \\
- & 8 & 48 & & 15 & 41 & \\
\hline
\end{tabular}

upstream 5'-ATTGGCAATGAGCGGTTC-3' and downstream 5'-GGATGCCACAGGACTCCAT-3'. qRT-PCR was performed with the SYBR Green PCR kit (TAKARA, Japan). By using $\beta$-actin as the internal control, the relative expression of the target genes was calculated by using the $2^{-\Delta \Delta \mathrm{Ct}}$ formula.

\section{Statistical methods}

All of the data were analyzed with the statistical software SPSS 21.0 (SPSS, Inc., Chicago, IL, USA). The enumerated data are presented as ratios or percentages, and intergroup comparisons were performed by using the Chi-square test. The data are presented as mean \pm standard deviation (SD). Student's- $t$ test was used for comparisons between two independent groups, and one-way ANOVA followed by Tukey's post hoc test was used to compare differences among more than two groups. A value of $p<0.05$ was considered statistically significant.

\section{Ethical statement}

This study was approved by the Ethics Committee of Linyi Central Hospital, and an informed consent form was signed by all patients prior to the study. All animals used in this study were cared for in accordance with the Guide for the Care and Use of Laboratory Animals published by the United States National Institute of Health (NIH publication no. 85-23, revised 1996) (Bayne 1996). The animal use protocol was reviewed and approved by the Institutional Animal Care and Use Committee (IACUC) of Linyi Central Hospital.

Table 2. The relationship between expressions of PD-1, PD-L1 and FOXP $3^{+}$Treg and clinicopathological characteristics of patients with ovarian cancer

\begin{tabular}{|c|c|c|c|c|c|c|c|c|c|c|}
\hline \multirow{2}{*}{$\begin{array}{l}\text { Clinicopathological } \\
\text { characteristics }\end{array}$} & \multirow{2}{*}{$n$} & \multicolumn{2}{|c|}{ PD-1 } & \multirow{2}{*}{$p$} & \multicolumn{2}{|c|}{ PD-L1 } & \multirow{2}{*}{$p$} & \multicolumn{2}{|c|}{ FOXP3 $^{+}$Tregs } & \multirow{2}{*}{$p$} \\
\hline & & - & + & & - & + & & - & + & \\
\hline Age & & & & 0.287 & & & 0.204 & & & 0.054 \\
\hline$\leq 55$ & 59 & 30 & 29 & & 24 & 35 & & 30 & 29 & \\
\hline$>55$ & 36 & 23 & 13 & & 20 & 16 & & 26 & 10 & \\
\hline Pathological type & & & & 0.374 & & & 0.18 & & & 0.372 \\
\hline serous & 66 & 39 & 27 & & 34 & 32 & & 41 & 25 & \\
\hline non-serous & 29 & 14 & 15 & & 10 & 19 & & 15 & 14 & \\
\hline Histological grading & & & & 0.046 & & & 0.004 & & & - \\
\hline high/medium & 65 & 41 & 24 & & 37 & 28 & & 45 & 20 & \\
\hline low & 30 & 12 & 18 & & 7 & 23 & & 11 & 19 & \\
\hline Clinical staging & & & & $<0.001$ & & & 0.006 & & & 0.004 \\
\hline I-II & 59 & 41 & 18 & & 34 & 25 & & 42 & 17 & \\
\hline III-IV & 36 & 12 & 24 & & 10 & 26 & & 14 & 22 & \\
\hline Lymph node metastasis & & & & 0.009 & & & $<0.001$ & & & 0.028 \\
\hline without & 62 & 41 & 21 & & 37 & 25 & & 42 & 20 & \\
\hline with & 33 & 12 & 21 & & 7 & 26 & & 14 & 19 & \\
\hline
\end{tabular}




\section{Results}

Expression of PD-1, PD-L1 and FOXP3 ${ }^{+}$Tregs in patients in each group

As shown in Figure 1, PD-L1, PD-1 and FOXP $3^{+}$Tregs were not present in cells in normal tissues, but their positive rates in OC tissues were significantly increased (all $p<0.05$ ). In addition, as shown in Table 1, in OC patients who expressed PD-L1 and PD-1 on cells, the number of patients who had $\mathrm{FOXP}^{+}$Tregs in cells was significantly higher than those who had no FOXP3 ${ }^{+}$Tregs in cells. In OC patients who expressed no PD-1 and PD-L1 on cells, the number of patients who had FOXP3 ${ }^{+}$Tregs in cells was apparently lower than that of patients who had no FOXP3 ${ }^{+}$Tregs in cells (all $p<0.05$ ), suggesting the positive correlation of PD-1 and PD-L1 expression with FOXP ${ }^{+}$Tregs.

Relationship of PD-1 and PD-L1 expression and FOXP $3^{+}$Tregs with the clinicopathological characteristics of patients with OC

The expression of PD-1 and PD-L1 and the presence of FOXP ${ }^{+}$Tregs showed no relationship with the age or types of pathology of OC patients (both $p>0.05$ ) but were significantly correlated with the clinical staging, histological grading and lymph node metastasis status of patients (all $p<0.05$ ) (Table 2). Specifically, patients with tumors with advanced stage and low differentiation and lymph node metastasis had
A

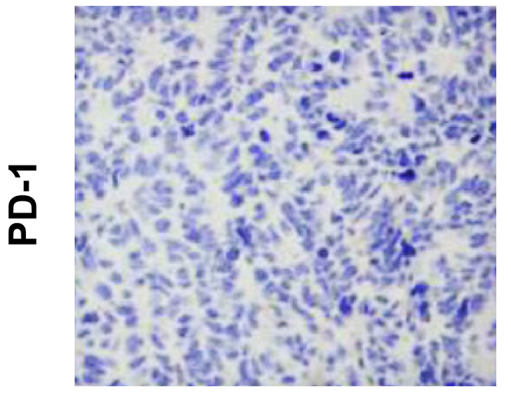

Normal

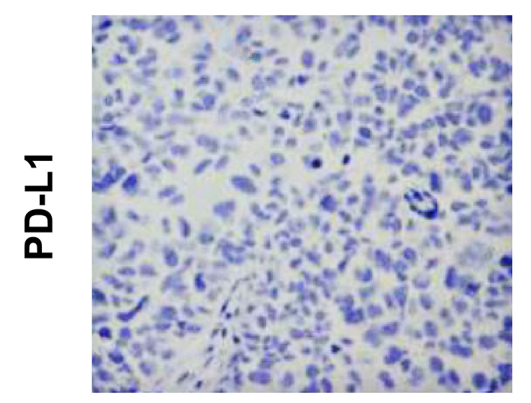

Normal

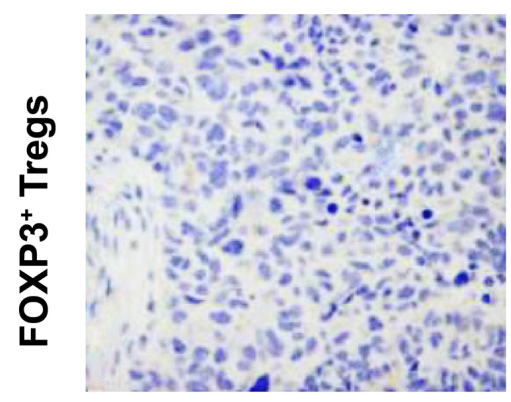

Normal

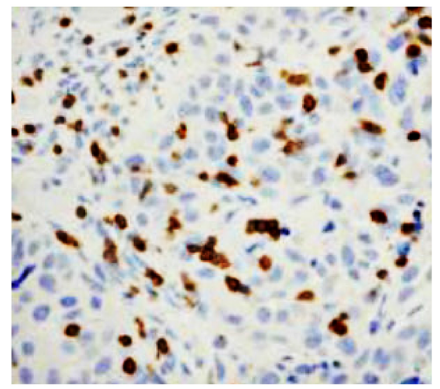

Ovarian cancer

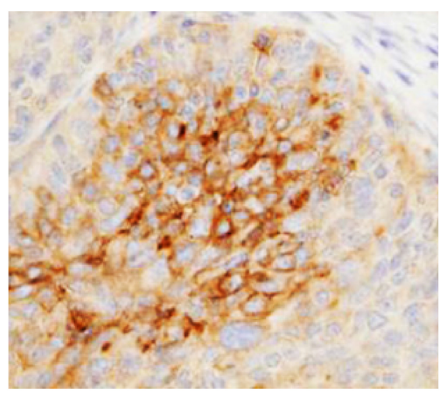

Ovarian cancer

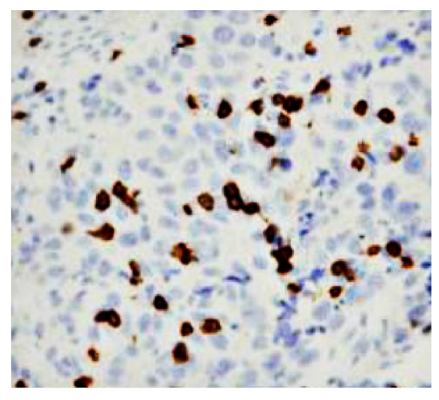

Ovarian cancer
B

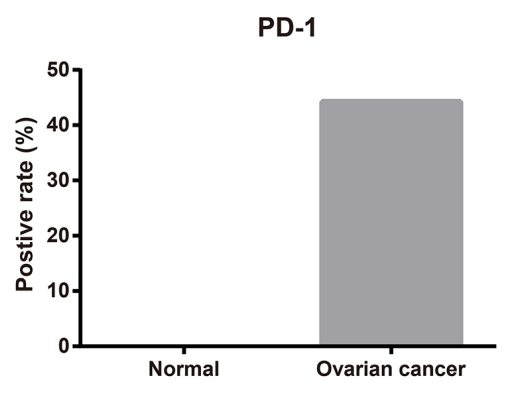

PD-L1

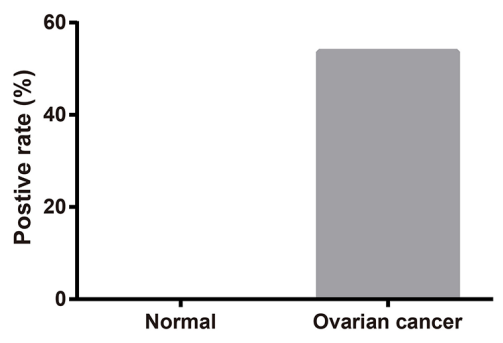

FOXP3 ${ }^{+}$Tregs

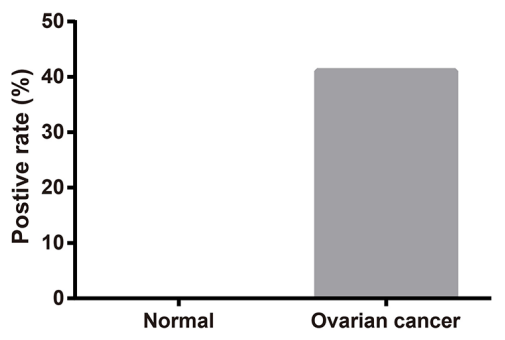

Figure 1. Immunohistochemical staining detected the expression of PD-1, PD-L1, and FOXP3 ${ }^{+}$Tregs in ovarian cancer tissues. A. Ovarian cancer and normal tissues were stained with anti-human PD-L1 mAb, anti-human PD-1 mAb, and mouse anti-human FOXP3 mAb for immunohistochemical staining. B. Quantitative results of the expression of PD-1, PD-L1, and FOXP3 ${ }^{+}$Tregs in ovarian cancer and normal tissues. 


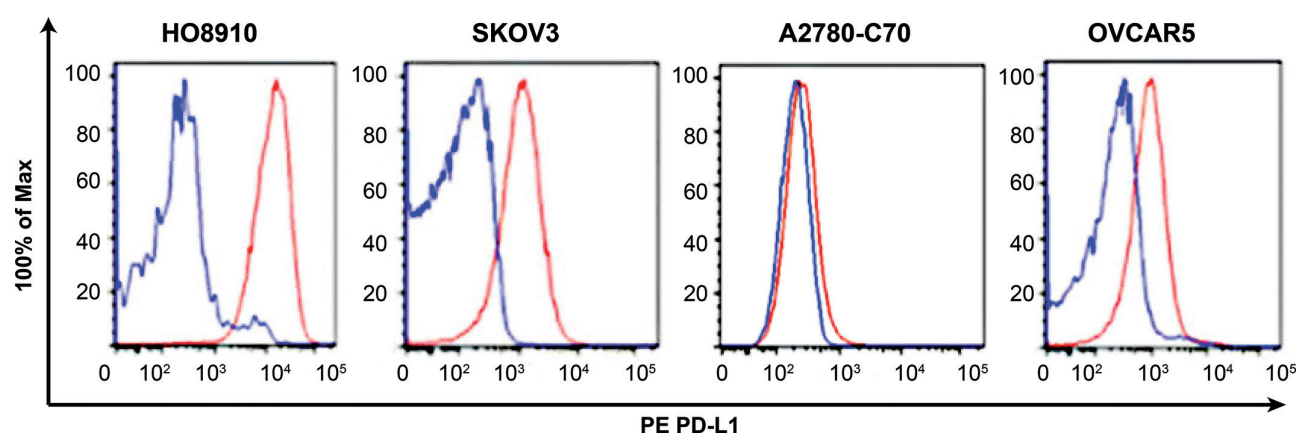

Figure 2. Expression of PD-L1 molecules on the surface of ovarian cancer cell lines (HO8910, OVCAR5, SKOV3, A2780-C70) was analyzed using a flow cytometer. Cells not labeled with antibodies were used as the negative controls (red line; the peaks on the right). PE, Phycoerythrin. (See online version for color figure.)

$\bar{A}$

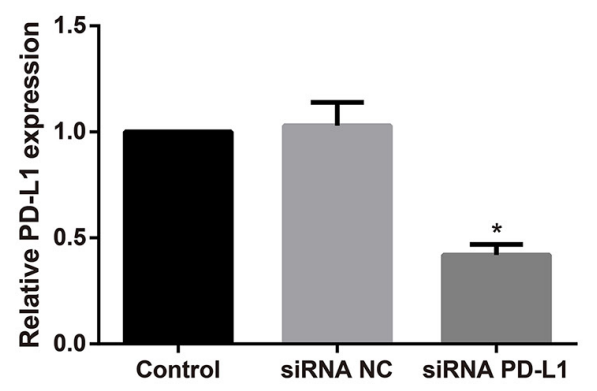

C

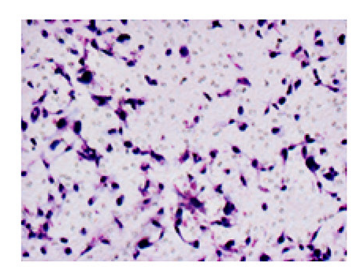

D

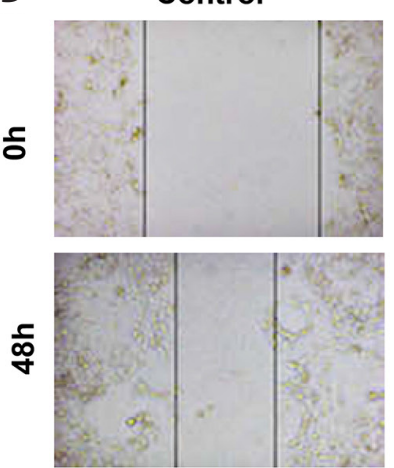

Control

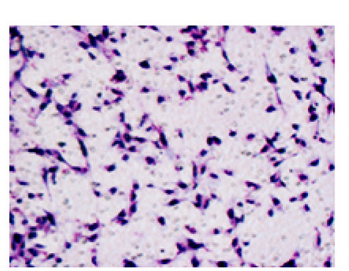

SIRNA NC
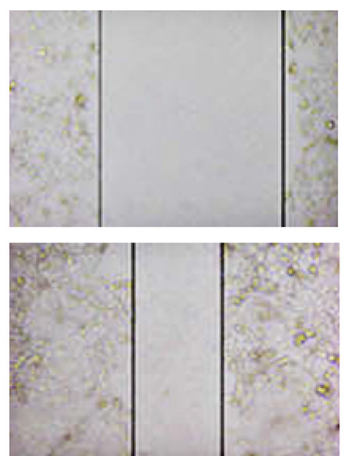

SIRNA NC
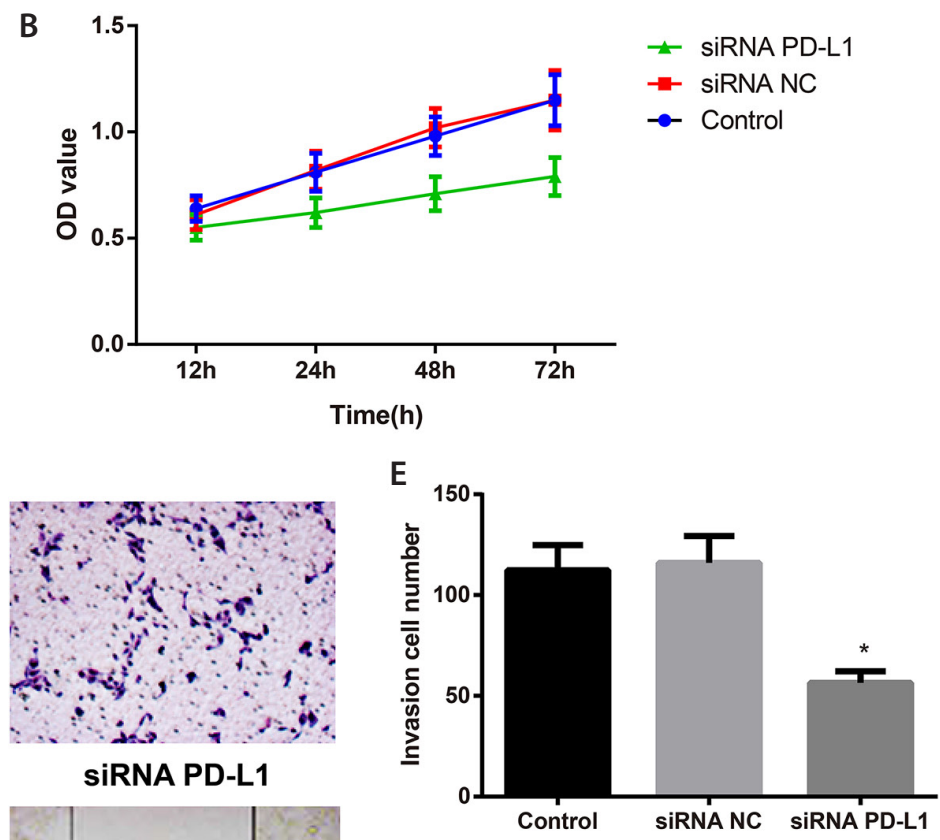

$\mathrm{F}$
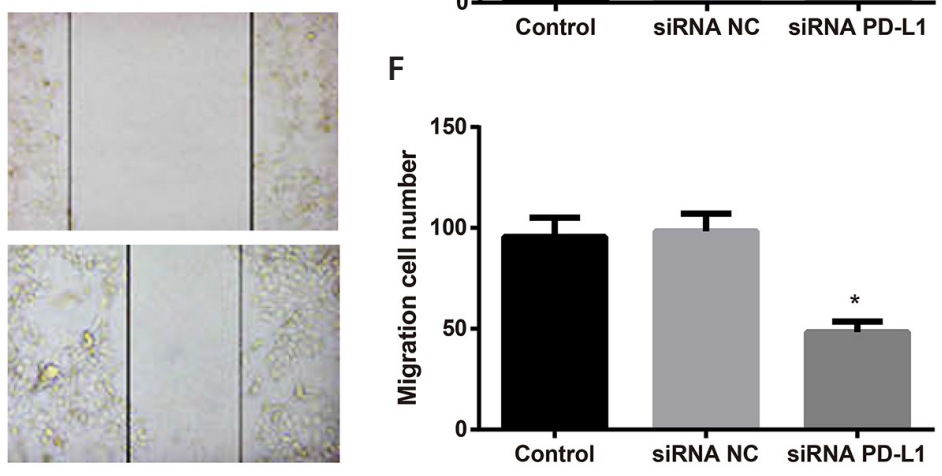

Figure 3. Effect of siRNA PD-L1 on the biological behaviors of ovarian cancer HO8910 cells. A. Relative PD-L1 expression in ovarian cancer cells of each group detected by qRT-PCR. B. Effect of siRNA PD-L1 on the proliferation of ovarian cancer cells determined by CCK-8 method. Invasion of ovarian cancer cells was analyzed by Transwell assay (C); migration by wound-healing assay (D). Statistical analysis of invasion $(\mathbf{E})$ and migration $(\mathbf{F})$ of ovarian cancer cells. ${ }^{*} p<0.05 v$ s. Control group. $p$ value was calculated using the one way ANOVA followed by Turkey post-hoc test. 
higher positive rates of the expression of PD-1 and PD-L1 and FOXP $3^{+}$Tregs in cells.

\section{PD-L1 expression in OC cell lines}

PD-L1 was not expressed on the surface of OC A2780-C70 cells but was the most highly expressed molecule on the surface of HO8910 cells, followed by SKOV3 cells and OVCAR5 cells, as illustrated in Figure 2. Therefore, the HO8910 cell line was chosen for subsequent experiments.

\section{Effect of PD-L1 siRNA on the biological behaviors of OC cells}

Compared with those in the Control group, PD-L1 expression and cell proliferation were not observably different in the siRNA NC group but were significantly decreased and inhibited in the PD-L1 siRNA group ( $p<0.05$; Fig. 3$)$. According to the Transwell assay, the ability of OC cells to penetrate the basal membrane was clearly decreased, and the number of invasive cells was remarkably decreased after transfection with PD-L1 siRNA (all $p<0.05$ ). The wound healing assay also demonstrated that the cell migration ability declined dramatically in PD-L1 siRNA group $(p<0.05)$ but did not show an obvious change in siRNA NC group when compared to that in Control group.

\section{Regulatory role of PD-L1 in Treg generation}

PBMCs and human T-cells were isolated, and the results showed that the purity of the isolated T-cells was above $90 \%$ (Fig. 4A). The Control group showed no TGF- $\beta$ expression, and the percentage of Tregs differentiated from T-cells was very low after the coculture of human peripheral $\mathrm{T}$-cells and OC cells. However, the percentage of Tregs in TGF- $\beta$ group was significantly higher than that in Control group $(p<0.05)$. In comparison with TGF- $\beta$ group, TGF- $\beta+$ antiPD-L1 group showed an obvious decline in the number of Tregs that differentiated from T-cells ( $p<0.05$; Fig. 4B, C).

\section{Establishment of the OC mouse model and the antitumor effect of anti-PD-L1 molecules}

Mice in anti-PD-L1 group showed delayed tumor formation, and the growth speed was significantly slower than
A

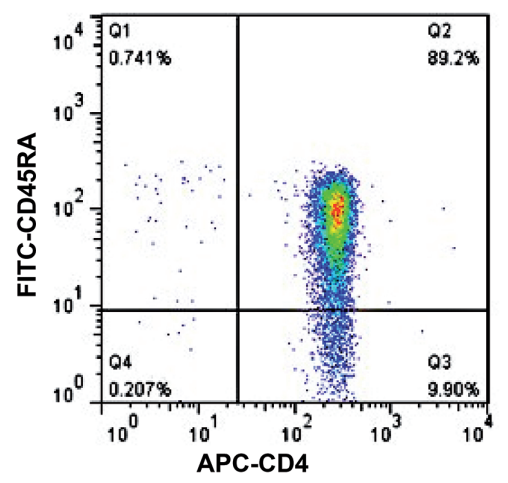

B

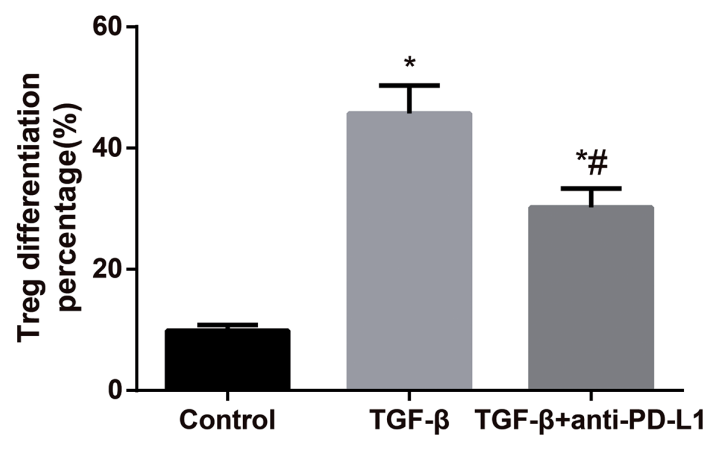

C

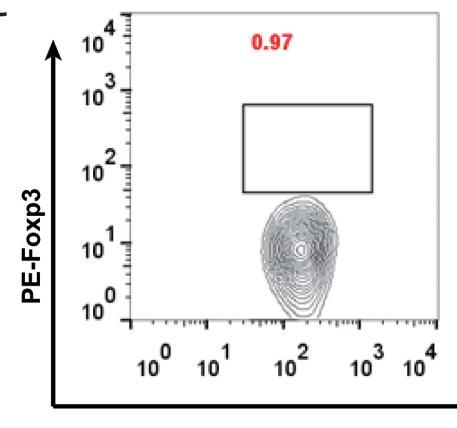

Control

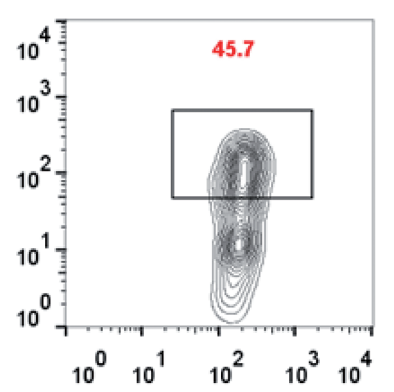

TGF- $\beta$

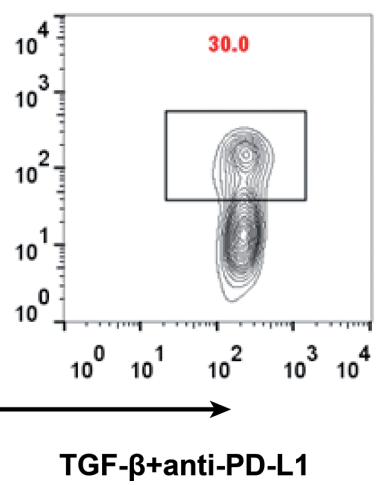

Figure 4. The differentiation of T-cells to Tregs measured by flow cytometry after three-day co-culture of ovarian cancer cells and T-cells. A. The purity of T-cells reached over $90 \%$ after magnetic-activated cell sorting (MACS). B. Comparison of the differentiation percentage of Tregs in each group. C. The differentiation percentage of Tregs detected by flow cytometry. ${ }^{*} p<0.05 v s$. Control group; ${ }^{*}, p<0.05 v s$. TGF- $\beta$ group. $p$ value was calculated using the one way ANOVA followed by Turkey post-hoc test. 
that of mice in Control group. The tumor growth curve is shown in Figure 5A. The expression levels of Tregs and FOXP3 in tumor tissues were detected by flow cytometry and qRT-PCR, which could reflect the recruitment of Tregs to the tumor microenvironment. According to the results, the expression levels of Tregs and FOXP3 in the tumor microenvironment were significantly reduced in mice in anti-PD-L1 group compared with those in Control group (all $p<0.05$; Fig. 5B).

A

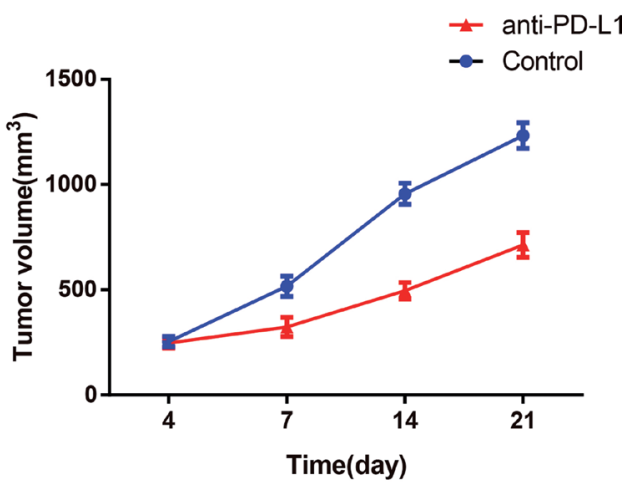

B

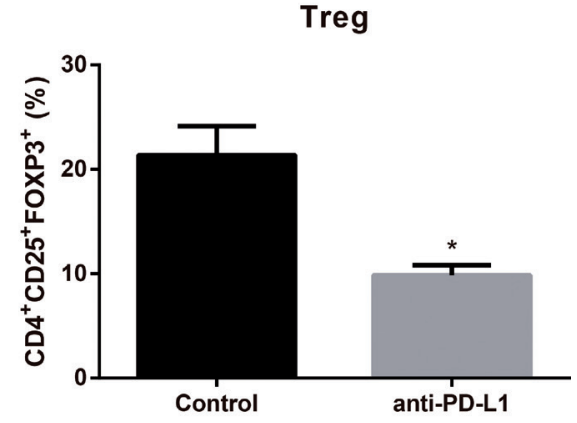

C

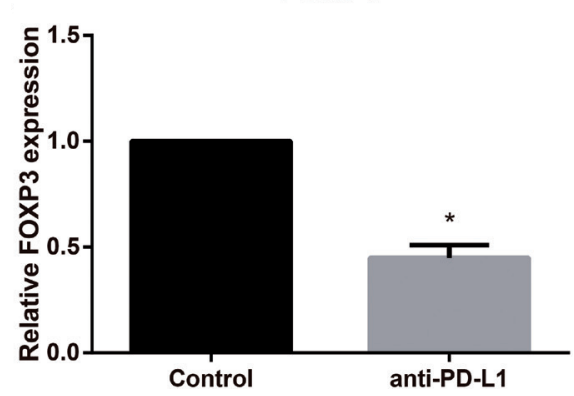

Figure 5. The therapeutic effect of anti-PD-L1 mAb on ovarian cancer mouse models. A. anti-PD-L1 mAb inhibited the growth of ovarian cancer in the body. B. Treg cell levels in tumor tissues detected by Flow cytometry. C. FOXP3 expression level in tumor tissues detected by $q R T-P C R .{ }^{*} p<0.05 v s$. Control group. $p$ value was calculated using the one way ANOVA followed by Turkey post-hoc test.

\section{Discussion}

First, PD-L1, PD-1 and FOXP3 ${ }^{+}$Tregs detected in the current study were not found in normal tissues but were found in OC cells, and OC patients with tumors with advanced stage and low differentiation and lymph node metastasis had much higher positive expression rates, which was similar to what we found in certain other types of cancers. For instance, Shi et al. (2011) observed a drastic increase in PD-1 expression in hepatocellular carcinoma tissues and T-cells, which gradually increased during disease progression. Maine et al. (2014) reported that OC patients had clearly increased PD-L1 expression on monocytes in ascites and blood as well as upregulated PD-1 expression on T-cells in the ascites and blood. On the other hand, Tregs have been demonstrated to exist in multiple tumors and to be highly expressed in colorectal cancer (Svensson et al. 2012), breast cancer (Wang et al. 2012), and gastric cancer (Yoshii et al. 2012) due to their immunosuppressive properties. Wolf and colleagues found that high FOXP3 expression in OC patients was associated with poor prognosis in terms of overall survival and progression-free survival (Wolf et al. 2005). Studies by Curiel et al. (2004) observed the significant accumulation of $\mathrm{CD} 4{ }^{+} \mathrm{CD} 25^{+} \mathrm{FOXP}^{+}$Tregs in malignant ascites and tumor tissues of OC patients, and Tregs were associated with a high death risk and reduced survival. Interestingly, we also found that the percentage of Tregs was related to tumor staging and patient survival, indicating that Tregs served as an immunological indicator for OC prognosis.

To date, the influence of PD-L1 in tumor tissues has been gradually revealed. For example, in lung cancer and colorectal cancer, the deletion of tumor suppressor gene phosphatase and tensin homolog deleted on chromosome 10 (PTEN) can induce the activation of the PTEN-PI3K-Akt signaling pathway, leading to high PD-L1 expression; because of this, PTEN deletion, to some degree, is regarded as the cause of high PD-L1 expression in tumors (Kondo et al. 2010; Xu et al. 2014). Under pathological conditions, the high expression of PD-1 is induced by the tumor microenvironment, and the binding of the PD-L1 ligand to PD-1 causes the continuous activation of the PD-1 pathway, playing a large role in the process of tumor immune escape (Kim and Chen 2016). Moreover, our study also revealed that the expression of PD-1 and PD-L1 was positively related to FOXP3 ${ }^{+}$Tregs. Ghebeh et al. (2006) also found that the number of Tregs was increased by the upregulation of PD-L1 in breast cancer, indicating a positive relationship between PD-L1 and Tregs. Therefore, in our study, we naturally hypothesized that PD-1, PD-L1 and Tregs may be related to the occurrence, progression and metastasis of OC.

Additionally, through coculturing the isolated human peripheral T-cells and the OC HO8910 cells in this work, we found that a higher percentage of Tregs differentiated 
from activated peripheral T-cells due to the coexistence of TGF- $\beta$ and OC cells. According to previous studies, TGF- $\beta$ could promote the differentiation and proliferation of Tregs, whereas an anti-TGF- $\beta$ specific antibody may significantly reduce the differentiation and immunosuppressive function of Tregs, suggesting that TGF- $\beta$ may act as an indispensable cytokine for the generation and inhibitory functioning of Tregs (Bommireddy and Doetschman 2007; Ni et al. 2012). However, when the anti-PD-L1 mAb was used to inhibit the PD-1/PD-L1 pathway, the percentage of T-cell-differentiated Tregs decreased significantly, indicating the important role of the PD-1/PD-L1 pathway in the differentiation and proliferation of Tregs. In agreement with our study, the differentiation of peripheral blood T-cells into CD4+ FOXP3 ${ }^{+}$ Tregs was elevated under the combined effects of anti-CD3, TGF- $\beta$ and PD-L1 in the work of Francisco et al. (2009). Additionally, the differentiation of Tregs was dependent on a PD-L1-mediated signaling pathway, as reported by Liu et al. (2013), and specifically inhibiting PD-L1 resulted in a reduction in Tregs and an increase in Treg apoptosis. Notably, the alteration of Akt/mTOR-related factors inhibited the transduction of T-lymphocyte activation signals and induced the differentiation of T-lymphocytes into Tregs (Zhao et al. 2007). FOXP 3 is a transcription factor that is only expressed on Tregs and that functions as a biomarker of Tregs (Ebert et al. 2008). PD-L1-promoted Treg cell immunosuppression may result from its enhancement and maintenance of FOXP3 expression in Tregs to sustain the survival and inhibitory function of Tregs (Francisco et al. 2009; Jiang et al. 2018). The binding of the $\mathrm{PD}-1$ receptor can also promote the conversion of Th $1^{+} \mathrm{CD}^{+}{ }^{+} \mathrm{T}$ cells into FOXP $3^{+}$Tregs (Zhou et al. 2010; Amarnath et al. 2011), showing that inhibiting the PD-1/PD-L1 pathway can block the generation of Tregs (Hu and Zhao 2013).

To the best of our knowledge, the infiltration of a large number of Tregs into the tumor microenvironment could inhibit the antitumor immune response to promote tumor growth (Mailloux and Young 2010). Our study also showed that OC HO8910 cells transfected with PD-L1 siRNA showed significantly decreased PD-L1 expression, proliferation, migration and invasion. After establishing a mouse model of OC, we observed a decreased tumor growth rate, a reduced percentage of Tregs, and the downregulation of FOXP3 in mice treated with anti-PD-L1. Consistent with the study by Zhao et al. (2017), inhibiting PD-L1 can suppress the growth of pancreatic cancer cells in mice. Pawłowska et al. (2019) reported that $\mathrm{PD}-1 / \mathrm{PD}-\mathrm{L} 1$ pathway blockade may be effective in suppressing cancer, especially the endometrioid type of OC. In addition, Preston et al. (2013) found that immunotherapeutic strategies that modify the ratios of $\mathrm{CD} 4{ }^{+} \mathrm{CD} 25^{+}$ $\mathrm{FOXP}^{+}$Tregs or $\mathrm{CD} 4^{+} \mathrm{CD} 25^{+} \mathrm{FOXP}^{-} \mathrm{T}$ cells to $\mathrm{CD}^{+}$effector cells may be useful in the improving outcomes of OC. Ou et al. (2018) indicated that a cancer vaccine combined with Treg modulation would be a promising approach to attain an effective antitumor response. The data from the above studies implied that successful OC therapy might require an attempt to reduce immunosuppressive mediators such as Tregs (Mougiakakos et al. 2010). Moreover, a previous study confirmed that blocking the PD-1/PD-L1 pathway can increase the function of effector CD8 T cells and inhibit the function of Tregs and bone marrow-derived inhibitory cells, thus enhancing the antitumor response (Lu et al. 2014; He et al. 2015). Taken together, the results indicate that inhibiting the PD-1/PD-L1 pathway may also exert antitumor effects on the growth of OC at least in part by inhibiting Treg proliferation and reducing tumor immune escape in the tumor microenvironment.

To conclude, the $\mathrm{PD} / \mathrm{PD}-\mathrm{L} 1$ pathway and FOXP $3^{+}$Tregs were activated in cells in OC tissues, and the inhibition of the PD/PD-L1 pathway could suppress the growth of ovarian tumors in part by repressing the differentiation of TGF- $\beta$-induced human peripheral T-cells into Tregs. Hence, this study provides a new perspective on the targeted immunotherapy of OC.

\section{Conclusion}

Inhibiting the PD-1/PD-L1 pathway by using the anti-PD-L1 $\mathrm{mAb}$ avelumab may exert inhibitory effects on the occurrence and progression of OC at least in part by hindering TGF- $\beta$ induced differentiation of human peripheral T-cells into Tregs.

Conflicts of interest. No potential conflicts of interest were disclosed.

\section{References}

Amarnath S, Mangus CW, Wang JC, Wei F, He A, Kapoor V, Foley JE, Massey PR, Felizardo TC, Riley JL, et al. (2011): The PDL1$\mathrm{PD} 1$ axis converts human TH1 cells into regulatory T cells. Sci. Transl. Med. 3, 111ra120

https://doi.org/10.1126/scitranslmed.3003130

Bayne K (1996): Revised guide for the care and use of laboratory animals available. American Physiological Society. Physiologist 39, 199, 208-111

Blank C, Mackensen A (2007): Contribution of the PD-L1/PD-1 pathway to T-cell exhaustion: an update on implications for chronic infections and tumor evasion. Cancer Immunol. Immunother. 56, 739-745 https://doi.org/10.1007/s00262-006-0272-1

Bommireddy R, Doetschman T (2007): TGFbeta1 and Treg cells: alliance for tolerance. Trends Mol. Med. 13, 492-501 https://doi.org/10.1016/j.molmed.2007.08.005

Boyerinas B, Jochems C, Fantini M, Heery CR, Gulley JL, Tsang KY, Schlom J (2015): Antibody-dependent cellular cytotoxicity activity of a novel anti-PD-L1 antibody avelumab 
(MSB0010718C) on human tumor cells. Cancer Immunol. Res. 3, 1148-1157 https://doi.org/10.1158/2326-6066.CIR-15-0059

Cho KR, Shih IeM (2009): Ovarian cancer. Annu. Rev. Pathol. 4, 287-313 https://doi.org/10.1146/annurev.pathol.4.110807.092246

Curiel TJ, Coukos G, Zou L, Alvarez X, Cheng P, Mottram P, Evdemon-Hogan M, Conejo-Garcia JR, Zhang L, Burow M, et al. (2004): Specific recruitment of regulatory T cells in ovarian carcinoma fosters immune privilege and predicts reduced survival. Nat. Med. 10, 942-949 https://doi.org/10.1038/nm1093

Ding Q, Lu L, Zhou X, Zhou Y, Chou KY (2011): Human PD-L1overexpressing porcine vascular endothelial cells induce functionally suppressive human CD4+CD25hi FOXP3+ Treg cells. J. Leukoc. Biol. 90, 77-86 https://doi.org/10.1189/jlb.1210691

Ebert LM, Tan BS, Browning J, Svobodova S, Russell SE, Kirkpatrick N, Gedye C, Moss D, Ng SP, MacGregor D, et al. (2008): The regulatory $\mathrm{T}$ cell-associated transcription factor FoxP3 is expressed by tumor cells. Cancer Res. 68, 3001-3009 https://doi.org/10.1158/0008-5472.CAN-07-5664

Fekonja A, Cretnik A, Zerdoner D, Takac I (2015): Hypodontia phenotype in patients with epithelial ovarian cancer. Radiol. Oncol. 49, 65-70 https://doi.org/10.2478/raon-2014-0034

Francisco LM, Salinas VH, Brown KE, Vanguri VK, Freeman GJ, Kuchroo VK, Sharpe AH (2009): PD-L1 regulates the development, maintenance, and function of induced regulatory $\mathrm{T}$ cells. J. Exp. Med. 206, 3015-3029 https://doi.org/10.1084/jem.20090847

Fujii R, Friedman ER, Richards J, Tsang KY, Heery CR, Schlom J, Hodge JW (2016): Enhanced killing of chordoma cells by antibody-dependent cell-mediated cytotoxicity employing the novel anti-PD-L1 antibody avelumab. Oncotarget 7, 33498-33511 https://doi.org/10.18632/oncotarget.9256

Gatalica Z, Snyder C, Maney T, Ghazalpour A, Holterman DA, Xiao N, Overberg P, Rose I, Basu GD, Vranic S, et al. (2014): Programmed cell death 1 (PD-1) and its ligand (PD-L1) in common cancers and their correlation with molecular cancer type. Cancer Epidemiol. Biomarkers Prev. 23, 2965-2970 https://doi.org/10.1158/1055-9965.EPI-14-0654

Ghebeh H, Mohammed S, Al-Omair A, Qattan A, Lehe C, AlQudaihi G, Elkum N, Alshabanah M, Bin Amer S, Tulbah A, et al. (2006): The B7-H1 (PD-L1) T lymphocyte-inhibitory molecule is expressed in breast cancer patients with infiltrating ductal carcinoma: correlation with important high-risk prognostic factors. Neoplasia 8, 190-198 https://doi.org/10.1593/neo.05733

Hafalla JC, Claser C, Couper KN, Grau GE, Renia L, de Souza JB, Riley EM (2012): The CTLA-4 and PD-1/PD-L1 inhibitory pathways independently regulate host resistance to Plasmodiuminduced acute immune pathology. PLoS Pathog. 8, e1002504 https://doi.org/10.1371/journal.ppat.1002504

Hafeez NA, Fouda Mel T, Abdel Gawad ER, Assar T, Mansour AI (2014): The role of regulatory T cells in preeclampsia. Egypt J. Immunol. 21, 45-55
Hamanishi J, Mandai M, Ikeda T, Minami M, Kawaguchi A, Murayama T, Kanai M, Mori $\mathrm{Y}$, Matsumoto $\mathrm{S}$, Chikuma $\mathrm{S}$, et al (2015): Safety and antitumor activity of Anti-PD-1 antibody, nivolumab, in patients with platinum-resistant ovarian cancer. J. Clin. Oncol. 33, 4015-4022 https://doi.org/10.1200/JCO.2015.62.3397

Hamid O, Robert C, Daud A, Hodi FS, Hwu WJ, Kefford R, Wolchok JD, Hersey P, Joseph RW, Weber JS, et al (2013): Safety and tumor responses with lambrolizumab (anti-PD-1) in melanoma. N. Engl. J. Med. 369, 134-144 https://doi.org/10.1056/NEJMoa1305133

Han SC, Kang GJ, Ko YJ, Kang HK, Moon SW, Ann YS, Yoo ES (2012): Fermented fish oil suppresses T helper $1 / 2$ cell response in a mouse model of atopic dermatitis via generation of CD4+CD25+ FOXP3+ T cells. BMC Immunol. 13, 44 https://doi.org/10.1186/1471-2172-13-44

Han SC, Koo DH, Kang NJ, Yoon WJ, Kang GJ, Kang HK, Yoo ES (2015): Docosahexaenoic acid alleviates atopic dermatitis by generating Tregs and IL-10/TGF-beta-modified macrophages via a TGF-beta-dependent mechanism. J. Invest. Dermatol. 135, 1556-1564 https://doi.org/10.1038/jid.2014.488

He J, Hu Y, Hu M, Li B (2015): Development of PD-1/PD-L1 pathway in tumor immune microenvironment and treatment for non-small cell lung cancer. Sci. Rep. 5, 13110 https://doi.org/10.1038/srep13110

Hou R, Yang Z, Wang S, Chu D, Liu Q, Liu J, Jiang L (2017): miR762 can negatively regulate menin in ovarian cancer. Onco. Targets Ther. 10, 2127-2137 https://doi.org/10.2147/OTT.S127872

Hsu C, Lee SH, Ejadi S, Even C, Cohen RB, Le Tourneau C, Mehnert JM, Algazi A, van Brummelen EMJ, Saraf S, et al (2017): Safety and antitumor activity of pembrolizumab in patients with programmed death-ligand 1-positive nasopharyngeal carcinoma: Results of the Keynote-028 study. J. Clin. Oncol. 35, 4050-4056 https://doi.org/10.1200/JCO.2017.73.3675

Hu ZQ, Zhao WH (2013): Critical role of PD-1/PD-L1 pathway in generation and function of follicular regulatory $\mathrm{T}$ cells. Cell Mol. Immunol. 10, 286-288 https://doi.org/10.1038/cmi.2013.15

Jacobs JF, Idema AJ, Bol KF, Nierkens S, Grauer OM, Wesseling P, Grotenhuis JA, Hoogerbrugge PM, de Vries IJ, Adema GJ (2009): Regulatory T cells and the PD-L1/PD-1 pathway mediate immune suppression in malignant human brain tumors. Neuro. Oncol. 11, 394-402 https://doi.org/10.1215/15228517-2008-104

Jiang L, Tang C, Gong Y, Liu Y, Rao J, Chen S, Qu W, Wu D, Lei L, Chen L (2018): PD-1/PD-L1 regulates Treg differentiation in pregnancy-induced hypertension. Braz. J. Med. Biol. Res. 51, e7334 https://doi.org/10.1590/1414-431x20187334

Kaku T, Ogawa S, Kawano Y, Ohishi Y, Kobayashi H, Hirakawa T, Nakano H (2003): Histological classification of ovarian cancer. Med. Electron Microsc. 36, 9-17 https://doi.org/10.1007/s007950300002

Keir ME, Butte MJ, Freeman GJ, Sharpe AH (2008): PD-1 and its ligands in tolerance and immunity. Annu Rev. Immunol. 26, 677-704 
https://doi.org/10.1146/annurev.immunol.26.021607.090331

Keyver-Paik MD, Zivanovic O, Rudlowski C, Holler T, Wolfgarten M, Kubler K, Schroder L, Mallmann MR, Polcher M, Kuhn W (2013): Interval debulking surgery in patients with Federation of Gynecology and Obstetrics (FIGO) stage IIIC and IV ovarian cancer. Onkologie 36, 324-332 https://doi.org/10.1159/000351256

Kim JM, Chen DS (2016): Immune escape to PD-L1/PD-1 blockade: seven steps to success (or failure). Ann. Oncol. 27, 1492-1504 https://doi.org/10.1093/annonc/mdw217

Kondo A, Yamashita T, Tamura H, Zhao W, Tsuji T, Shimizu M, Shinya E, Takahashi H, Tamada K, Chen L, et al (2010): Interferon-gamma and tumor necrosis factor-alpha induce an immunoinhibitory molecule, B7-H1, via nuclear factor-kappaB activation in blasts in myelodysplastic syndromes. Blood 116, 1124-1131

https://doi.org/10.1182/blood-2009-12-255125

Kumar R, Collins D, Dolly S, McDonald F, O‘Brien MER, Yap TA (2017): Targeting the PD-1/PD-L1 axis in non-small cell lung cancer. Curr. Probl. Cancer 41, 111-124

https://doi.org/10.1016/j.currproblcancer.2016.12.002

Liu H, Bakthavatsalam R, Meng Z, Li Z, Li W, Perkins JD, Reyes $J$ (2013): PD-L1 signal on liver dendritic cells is critical for FOXP3(+)CD4(+)CD25(+) Treg and liver tolerance induction in mice. Transplant. Proc. 45, 1853-1855 https://doi.org/10.1016/j.transproceed.2013.03.015

Lu L, Xu X, Zhang B, Zhang R, Ji H, Wang X (2014): Combined PD-1 blockade and GITR triggering induce a potent antitumor immunity in murine cancer models and synergizes with chemotherapeutic drugs. J. Transl. Med. 12, 36 https://doi.org/10.1186/1479-5876-12-36

Mailloux AW, Young MR (2010): Regulatory T-cell trafficking: from thymic development to tumor-induced immune suppression. Crit. Rev. Immunol. 30, 435-447 https://doi.org/10.1615/CritRevImmunol.v30.i5.30

Maine CJ, Aziz NH, Chatterjee J, Hayford C, Brewig N, Whilding L, George AJ, Ghaem-Maghami S (2014): Programmed death ligand-1 over-expression correlates with malignancy and contributes to immune regulation in ovarian cancer. Cancer Immunol. Immunother. 63, 215-224

https://doi.org/10.1007/s00262-013-1503-x

Mehnert JM, Varga A, Brose MS, Aggarwal RR, Lin CC, Prawira A, de Braud F, Tamura K, Doi T, Piha-Paul SA, et al (2019): Safety and antitumor activity of the anti-PD-1 antibody pembrolizumab in patients with advanced, PD-L1-positive papillary or follicular thyroid cancer. BMC Cancer 19, 196 https://doi.org/10.1186/s12885-019-5380-3

Mougiakakos D, Choudhury A, Lladser A, Kiessling R, Johansson CC (2010): Regulatory T cells in cancer. Adv. Cancer Res. 107, 57-117 https://doi.org/10.1016/S0065-230X(10)07003-X

Ni XY, Sui HX, Liu Y, Ke SZ, Wang YN, Gao FG (2012): TGF-beta of lung cancer microenvironment upregulates B7H1 and GITRL expression in dendritic cells and is associated with regulatory $\mathrm{T}$ cell generation. Oncol. Rep. 28, 615-621

https://doi.org/10.3892/or.2012.1822

Nowicki TS, Akiyama R, Huang RR, Shintaku IP, Wang X, Tumeh PC, Singh A, Chmielowski B, Denny C, Federman N, Ribas A
(2017): Infiltration of CD8 T cells and expression of PD-1 and PD-L1 in synovial sarcoma. Cancer Immunol. Res. 5, 118-126 https://doi.org/10.1158/2326-6066.CIR-16-0148

Okazaki T, Honjo T (2007): PD-1 and PD-1 ligands: from discovery to clinical application. Int. Immunol. 19, 813-824 https://doi.org/10.1093/intimm/dxm057

Ou Y, Cannon MJ, Nakagawa M (2018): Regulatory T cells in gynecologic cancer. MOJ Immunol. 6, 34-42 https://doi.org/10.15406/moji.2018.06.00189

Pai SI, Zandberg DP, Strome SE (2016): The role of antagonists of the PD-1:PD-L1/PD-L2 axis in head and neck cancer treatment. Oral Oncol. 61, 152-158 https://doi.org/10.1016/j.oraloncology.2016.08.001

Pawlowska A, Suszczyk D, Okla K, Barczynski B, Kotarski J, Wertel I (2019): Immunotherapies based on PD-1/PD-L1 pathway inhibitors in ovarian cancer treatment. Clin. Exp. Immunol. 195, 334-344 https://doi.org/10.1111/cei.13255

Polanczyk MJ, Hopke C, Vandenbark AA, Offner H (2007): Treg suppressive activity involves estrogen-dependent expression of programmed death-1 (PD-1). Int. Immunol. 19, 337-343 https://doi.org/10.1093/intimm/dxl151

Preston CC, Maurer MJ, Oberg AL, Visscher DW, Kalli KR, Hartmann LC, Goode EL, Knutson KL (2013): The ratios of CD8+ T cells to CD4+CD25+ FOXP3+ and FOXP3- T cells correlate with poor clinical outcome in human serous ovarian cancer. PLoS One 8, e80063 https://doi.org/10.1371/journal.pone.0080063

Pujade-Lauraine E, Fujiwara K, Dychter SS, Devgan G, Monk BJ (2018): Avelumab (anti-PD-L1) in platinum-resistant/refractory ovarian cancer: JAVELIN Ovarian 200 Phase III study design. Future Oncol. 14, 2103-2113 https://doi.org/10.2217/fon-2018-0070

Sakaguchi S (2008): Regulatory T cells in the past and for the future. Eur. J. Immunol. 38, 901-937 https://doi.org/10.1002/eji.200890012

Shi F, Shi M, Zeng Z, Qi RZ, Liu ZW, Zhang JY, Yang YP, Tien P, Wang FS (2011): PD-1 and PD-L1 upregulation promotes CD8(+) T-cell apoptosis and postoperative recurrence in hepatocellular carcinoma patients. Int. J. Cancer. 128, 887-896 https://doi.org/10.1002/ijc.25397

Siegel RL, Miller KD, Jemal A (2018): Cancer statistics, 2018. CA Cancer J. Clin. 68, 7-30

https://doi.org/10.3322/caac. 21442

Svensson H, Olofsson V, Lundin S, Yakkala C, Bjorck S, Borjesson L, Gustavsson B, Quiding-Jarbrink M (2012): Accumulation of CCR4(+)CTLA-4 FOXP3(+)CD25(hi) regulatory T cells in colon adenocarcinomas correlate to reduced activation of conventional T cells. PLoS One 7, e30695 https://doi.org/10.1371/journal.pone.0030695

Tang L, Yang J, Ng SK, Rodriguez N, Choi PW, Vitonis A, Wang K, McLachlan GJ, Caiazzo RJ, Jr, Liu BC, et al (2010): Autoantibody profiling to identify biomarkers of key pathogenic pathways in mucinous ovarian cancer. Eur. J. Cancer 46, 170-179 https://doi.org/10.1016/j.ejca.2009.10.003

Topalian SL, Drake CG, Pardoll DM (2012): Targeting the PD-1/ B7-H1(PD-L1) pathway to activate anti-tumor immunity. Curr. Opin. Immunol. 24, 207-212 
https://doi.org/10.1016/j.coi.2011.12.009

Wang ZK, Yang B, Liu H, Hu Y, Yang JL, Wu LL, Zhou ZH, Jiao SC (2012): Regulatory T cells increase in breast cancer and in stage IV breast cancer. Cancer Immunol. Immunother. 61, 911-916 https://doi.org/10.1007/s00262-011-1158-4

Webb JR, Milne K, Kroeger DR, Nelson BH (2016): PD-L1 expression is associated with tumor-infiltrating $\mathrm{T}$ cells and favorable prognosis in high-grade serous ovarian cancer. Gynecol. Oncol. 141, 293-302 https://doi.org/10.1016/j.ygyno.2016.03.008

Wefers C, Lambert LJ, Torensma R, Hato SV (2015): Cellular immunotherapy in ovarian cancer: Targeting the stem of recurrence. Gynecol. Oncol. 137, 335-342 https://doi.org/10.1016/j.ygyno.2015.02.019

Wolf D, Wolf AM, Rumpold H, Fiegl H, Zeimet AG, Muller-Holzner E, Deibl M, Gastl G, Gunsilius E, Marth C (2005): The expression of the regulatory $\mathrm{T}$ cell-specific forkhead box transcription factor FoxP3 is associated with poor prognosis in ovarian cancer. Clin. Cancer Res. 11, 8326-8331 https://doi.org/10.1158/1078-0432.CCR-05-1244

Wolf D, Sopper S, Pircher A, Gastl G, Wolf AM (2015): Treg(s) in cancer: Friends or foe? J. Cell Physiol. 230, 2598-2605 https://doi.org/10.1002/jcp.25016

Xu C, Fillmore CM, Koyama S, Wu H, Zhao Y, Chen Z, HerterSprie GS, Akbay EA, Tchaicha JH, Altabef A, et al (2014): Loss of Lkb1 and Pten leads to lung squamous cell carcinoma with elevated PD-L1 expression. Cancer Cell 25, 590-604 https://doi.org/10.1016/j.ccr.2014.03.033
Yoshida H, Sumi T, Zhi X, Yasui T, Honda K, Ishiko O (2011): Claudin-4: a potential therapeutic target in chemotherapy-resistant ovarian cancer. Anticancer Res. 31, 1271-1277

Yoshii M, Tanaka H, Ohira M, Muguruma K, Iwauchi T, Lee T, Sakurai K, Kubo N, Yashiro M, Sawada T, Hirakawa K (2012): Expression of Forkhead box P3 in tumour cells causes immunoregulatory function of signet ring cell carcinoma of the stomach. Br. J. Cancer 106, 1668-1674 https://doi.org/10.1038/bjc.2012.141

Zhao L, Li C, Liu F, Zhao Y, Liu J, Hua Y, Liu J, Huang J, Ge C (2017): A blockade of $\mathrm{PD}-\mathrm{L} 1$ produced antitumor and antimetastatic effects in an orthotopic mouse pancreatic cancer model via the PI3K/Akt/mTOR signaling pathway. Onco. Targets Ther. 10, 2115-2126 https://doi.org/10.2147/OTT.S130481

Zhao Y, Huang Z, Qi M, Lazzarini P, Mazzone T (2007): Immune regulation of $\mathrm{T}$ lymphocyte by a newly characterized human umbilical cord blood stem cell. Immunol. Lett. 108, 78-87 https://doi.org/10.1016/j.imlet.2006.10.007

Zhou Q, Munger ME, Highfill SL, Tolar J, Weigel BJ, Riddle M, Sharpe AH, Vallera DA, Azuma M, Levine BL, et al (2010): Program death-1 signaling and regulatory $\mathrm{T}$ cells collaborate to resist the function of adoptively transferred cytotoxic $\mathrm{T}$ lymphocytes in advanced acute myeloid leukemia. Blood 116, 2484-2493

https://doi.org/10.1182/blood-2010-03-275446

Received: July 1, 2019

Final version accepted: February 20, 2020 